\title{
Machine Learning Prediction of USA Export to PRC in Context of Mutual Sanction
}

\author{
Tomáš Krulický1 ${ }^{1}$ Eva Kalinová1, Jiří Kučera ${ }^{1}$ \\ ${ }^{1}$ Institute of Technology and Business in České Budějovice, School of Expertness and \\ Valuation, Czech Republic
}

\begin{abstract}
On the basis of the time series data, machine learning can also be used for predicting the future development of export in various states. It offers, of course, to measure trade between the world's two largest economies - China and the USA, which has an impact on the global world economy. Therefore, the objective of this contribution is to predict the USA export to the People's Republic of China in the context of mutual sanctions using machine learning. The data set contains monthly data on the development of the USA export to China between January 2000 and July 2019. Regression is carried out using neural networks. There are generated three sets of multilayer perceptron networks considering the time series lag of 1 month, 5 months, and 10 months. A total of 10,000 neural structures are generated, out of which 5 with the best characteristics are retained. Export values between August 2019 and December 2020 are predicted and subsequently, the results of all three experiments are compared. The result closes to the ideal one is with the time series lag of 10 months; the networks are also able to capture the trend and fluctuations of the time series. Yet, there is certain overfitting notable, mainly due to the gradation of mutual trade war between the USA and the PRC.
\end{abstract}

Keywords: machine learning, export, prediction, artificial neural networks, time series

\section{Introduction}

In an article, Bernhofen et al. (2018) recounted trade policy change of a country is usually gradual. For developing economies, trade policy changes always go with initiation of a national policy reform strategy. Between 2004 and 2005 previously textile quota-bound products experienced a $155 \%$ growth in export value, while non-quota products 
experienced a 61\% growth. Global Imports from China between 1990 and 2010 rose from $2 \%$ to $11 \%$. This rise is even greater for the U.S, rising from $3 \%$ to $19 \%$ (Handley and Limao, 2017). The tenfold increase in the share of U.S manufacturing expenditure on Chinese goods has contributed to a decrease in U.S prices (Auer and Fischer, 2010), manufacturing employment, and local wages (David et al., 2013). On the other hand, in Doan and Long's, (2019) opinion, contribution of US imports from China to job creation has improved meaningfully, mainly in manufacturing and agriculture.

Machine predictions facilitate businesses to make exact suppositions with accurate presumable results of an inquiry dependent on recorded facts. In fact, numerous studies have revealed that machine learning model prevails against time series models because it works better with volatile and irregular series as put forward by Ülke et al. (2018). For instance, extreme learning machine can be utilized effectively to forecast GDP growth rate as purported by Sokolov-Mladenović et al. (2016).

The objective of the contribution is to forecast the export of the United States of America (USA) in the People's Republic of China (PRC) using machine learning.

\section{Literary Research}

China's import duty advancement on normal trade may affect Chinese firms and trigger intra-industry asset reallocation towards firms with high capital power. Firms import contributions with more noteworthy multifaceted nature comes from nations with higher salary per capita, such instances holds just for customary imports not for imports for export progression as claimed by Wang and Yu (2012). Rodrigue and Tan (2019) put forward that corporations sales growth is directly related to product quality upgrading, and trade emancipation affects margins through which businesses strive for clients over time.

Over the years, China's rapid penetration of U.S product markets increased dramatically. It is reported that China was present in just 9\% of all manufacturing product categories in 1972, it was present in 85\% of categories by 2005 (Schott, 2008). Assessing the impact of trade policy uncertainty (TPU), Handley and Limao (2017) informed that increased TPU reduces investment in export entry and technology upgrading, also believed to reduce trade flows and real income for consumers.

Trade among the U.S and China have triggered significant loss of job; which researchers believe cannot be handled by realigning labor in viable industries in the United States. Decades ago, 64,000 American workers were employed in production associated to China's export to the U.S in contrast to 186,000 Chinese workers employed in the U.S export to China (Lin et al., 2018). This finding is not that different from that put forward by Feenstra and Sasahara (2018) recounting a reduction in labor demand of 1.4 million jobs in manufacturing and 0.6 million in services, for total job losses of 2.0 million between 1995-2011. 
Li et al. (2019) proposed that China's export economy has become more diversified and has evolved from polarized structure to relatively balanced system.

This paper presents machine predictions, U.S-China exports and imports relation. In the vein of Hummels and Klenow (2005) and Hallak (2006) larger rich economies like the United States export from countries that produce good quality products more than smaller economies. The literatures reviewed demonstrates that mechanical, agricultural, and technological US exports to China sharply increased over the past decade. According to the literatures, the following can be concluded: (1) China is one of the biggest US export partner regardless of mutual sanctions, (2) Using time series data, machine learning techniques can be used to predict future US-China export, (3) US exports to China is a driver of employment growth in the PR China.

\section{Methods and Data}

Mutual trade restrictions of the USA and PRC caused by the USA feeling of imbalance of the two countries mutual trade significantly influence the overall climate of the international trade. The US leaders decided to regulate the mutual trade by imposing duties on specific types of traded goods. The PRC leaders accepted this policy over time and started to introduce retaliatory measures. The whole situation raises tension between both countries and affects the development of overall trade balance, import and export. Given that the USA started the war, it can be assumed that the first quantity affected will be the USA import from the PRC. Retaliatory measures from the side of the PRC are expected to cause the decrease of the USA export to the PRC. The time series of this variable will thus show fluctuations of an extraordinary character. This makes it an interesting object for the investigation of time series, or their machine learning prediction.

The dataset demonstrates the time series course at monthly intervals between January 2000 and July 2019. The course of the time series is shown in Graph 1. 
Graph 1: Development of USA export to PRC between January 2000 and July 2019

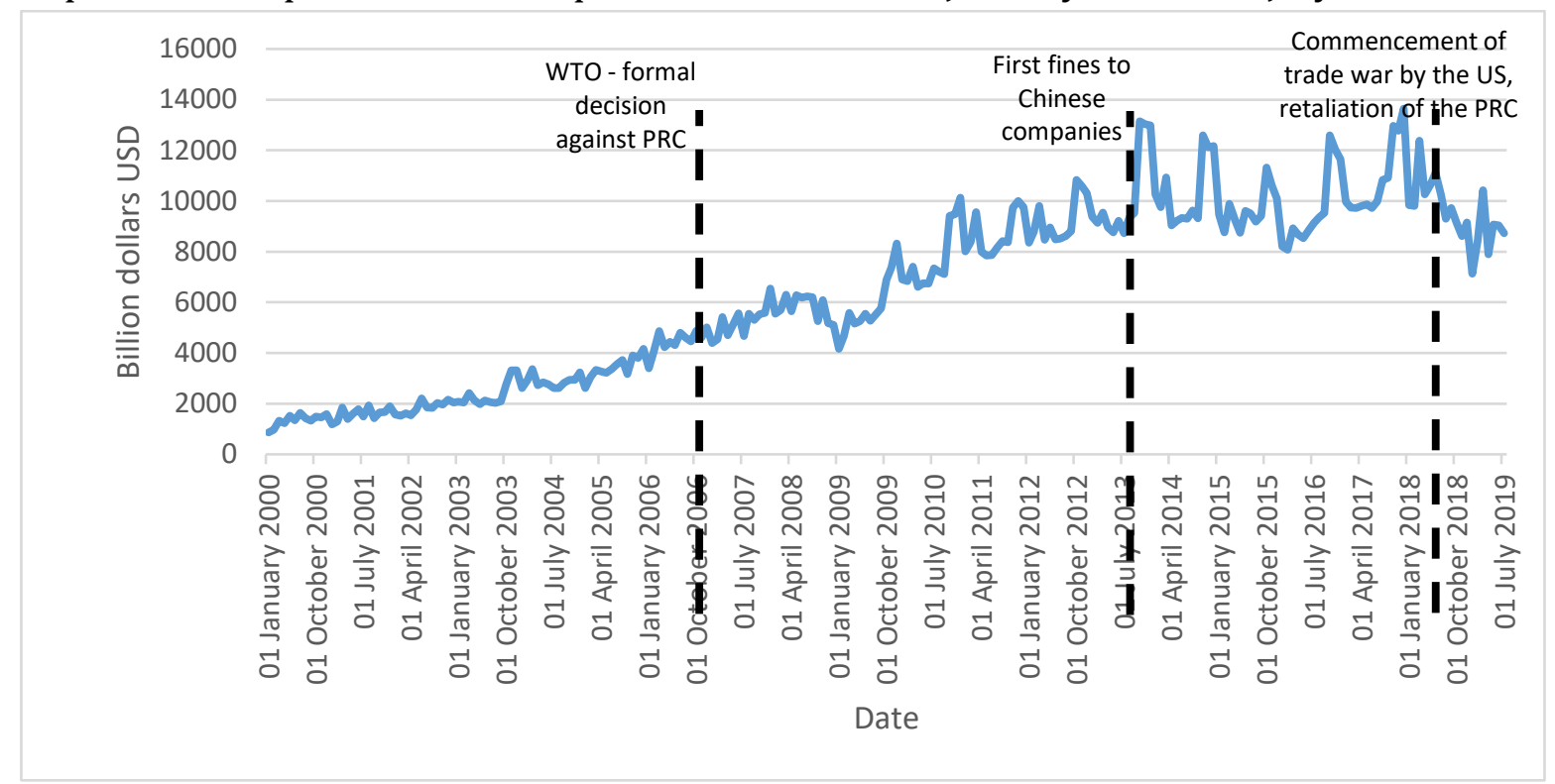

Note: The values (in the whole text) are given in USD billion.

Source: Authors.

The graph clearly shows the fluctuations within the individual years of the monitored period. However, the question is whether these are regular seasonal fluctuations or random events caused by poor long-term trade relationships between American and Chinese business partners. Although the USA export to the PRC is realized, it seems as if it is random rather than planned activity, or even long-term planned activity. However, only when the time series is examined, it will be clear whether it is a seasonal fluctuation in the development of the time series. However, the increase in the development of the variable is particularly evident. Taking into account the highest value achieved before the outbreak of the trade war, the USA export to the PRC achieved the amount of USD 13,644.8 billion USD. At the beginning of the monitored period, the value was USD 863.1 billion. The difference is thus nearly sixteen times higher. When the trade war burst out, the USA export to the PRC decreased from the aforementioned USD 13,644.8 billion USD to USD $7,134.4$ billion. Although there has been a slight increase, the return to the values achieved before the launching of the trade war cannot be expected. Table 1 shows the basic statistical characteristics of the dataset. 
Tab. 1: Basic statistical characteristics of the examined dataset

\begin{tabular}{|l|r|r|r|r|}
\hline \multicolumn{1}{|c|}{ Statistics } & \multicolumn{1}{c|}{$\begin{array}{c}\text { Date (input } \\
\text { variable) }\end{array}$} & $\begin{array}{c}\text { Month (Output } \\
\text { variable) }\end{array}$ & $\begin{array}{c}\text { Year (Input } \\
\text { variable) }\end{array}$ & $\begin{array}{c}\text { Export (Output } \\
\text { variable (target)) }\end{array}$ \\
\hline Minimum (Training) & $36,556.00$ & 1.00000 & 2000.000 & 863.10 \\
\hline Maximum (Training) & $43,646.00$ & 12.00000 & 2019.000 & $13,147.80$ \\
\hline Mean (Training) & $40,050.47$ & 6.45455 & 2009.115 & $6,415.19$ \\
\hline Standard deviation (Training) & $2,001.16$ & 3.50688 & 5.473 & $3,382.42$ \\
\hline Minimum (Testing) & $36,585.00$ & 1.00000 & 2000.000 & 972.70 \\
\hline Maximum (Testing) & $43,677.00$ & 12.00000 & 2019.000 & $12,382.10$ \\
\hline Mean (Testing) & $40,130.09$ & 6.00000 & 2009.371 & $5,918.11$ \\
\hline Standard deviation (Testing) & $2,418.96$ & 3.38683 & 6.691 & $3,492.76$ \\
\hline Minimum (Validation) & $36,646.00$ & 1.00000 & 2000.000 & $1,227.50$ \\
\hline Maximum (Validation) & $43,373.00$ & 12.00000 & 2018.000 & $13,644.80$ \\
\hline Mean (Validation) & $40,412.86$ & 6.71429 & 2010.086 & $7,025.04$ \\
\hline Standard deviation (Validation) & $3,403.28$ & 3.44159 & 9.284 & $5,528.71$ \\
\hline Minimum (Overall) & $36,556.00$ & 1.00000 & 2000.000 & 863.10 \\
\hline Maximum (Overall) & $43,677.00$ & 12.00000 & 2019.000 & $13,644.80$ \\
\hline Mean (Overall) & $40,116.30$ & 6.42553 & 2009.298 & $6,431.99$ \\
\hline Standard deviation (Overall) & $2,069.19$ & 3.45140 & 5.669 & $3,429.19$ \\
\hline
\end{tabular}

Source: Authors.

There will be carried out a regression using neural structures. We will generate multilayer perceptron networks (MLP). Three sets of artificial neural networks will be generated that will differ according to the lag in time series considered:

1. One-month lag in time series,

2. Five-month lag in time series,

3. Ten-month lag in time series.

Time series lag indicates the number of data used for the calculation of a following value (that is, in the first case, it is based on the value for one preceding month, in the second case it is based on the five preceding values, in the third case, based on the outcomes of ten preceding months). Larger time series lag can indicate averaging values, while small lag can result in extreme fluctuations of a smoothed time series. Each lag entails greater demands on the complexity of artificial neural network structure, specifically the neurons in the input layer (in Experiment 1, the input layer will contain 3 neurons, in Experiment 2, there will be 15 neurons, and in Experiment 3, 30 neurons). Other settings will be the same for all three experiments.

The continuous variable will be time. Seasonal fluctuations will be represented by a categorical variable (month and year in which the value was measured). We will thus work with possible monthly seasonality of the time series. However, it is also important to capture the overall trend of the time series. The dependent variable will be the USA import from the PRC. 
The time series will be divided into three sets - Training, Testing, and Validation dataset. The first dataset will contain $70 \%$ of the input data. Based on the training dataset, neural structures will be generated. The remaining two datasets will contain $15 \%$ of the input information each, and both sets will be used for the verification of the reliability of the found neural structure, or model. A total of 10,000 neural networks will be generated, out of which 5 with the best characteristics ${ }^{1}$ will be retained. The hidden layer will contain from 2 to 12 neurons for Experiment 1, 1-15 neurons for Experiments 2 and 3. In the hidden and output layers, the following distribution functions will be considered: Linear, Logistic, Atanh, Exponential, Sinus.

Other settings will remain default (according to ANS tool - automated neural structures). The expected outcomes of the analysis will be the following ones:

- The overview of retained networks: it will always contain the structures of five retained neural networks, performance of datasets, errors, error function, activation function of hidden and output layer of neural network.

- Correlation coefficients: they characterize the performance of the network in individual data subsets.

- Basic statistics of smoothed time series.

- Graph of smoothed time series.

- Predicted values for the period between August 2019 and December 2020.

- Graph of the development of actual time series connected with predictions, i.e. a possible course of the time series between January 2000 and December 2020.

Finally, the results of three experiments carried out will be compared and it will be decided whether the chosen methodology of machine learning is appropriate in terms of the direction. Also, the time lag closest to the correct result will be identified.

\footnotetext{
${ }^{1}$ The least squares method will be used. Generation of networks will be finished if there is no improvement, i.e. no reduction in the sum of squares. We will retain the neural structures whose sum of residuals squares to the actual USA export to the PRC is as low as possible (zero ideally).
} 


\section{Results}

\section{Experiment 1 (1-month lag in time series)}

Table 2 shows the overview of neural networks retained from Experiment 1.

Tab. 2: Retained neural networks from Experiment 1

\begin{tabular}{|c|c|c|c|c|c|c|c|c|c|c|c|}
\hline Index & $\begin{array}{c}\text { Networ } \\
\mathbf{k}\end{array}$ & $\begin{array}{c}\text { Training } \\
\text { perform. }\end{array}$ & $\begin{array}{c}\text { Testing } \\
\text { perform. }\end{array}$ & $\begin{array}{c}\text { Valid. } \\
\text { perform. }\end{array}$ & $\begin{array}{c}\text { Training } \\
\text { error }\end{array}$ & $\begin{array}{c}\text { Testing } \\
\text { error }\end{array}$ & $\begin{array}{c}\text { Valid. } \\
\text { error }\end{array}$ & $\begin{array}{c}\text { Training } \\
\text { algorithm }\end{array}$ & $\begin{array}{c}\text { Error } \\
\text { function }\end{array}$ & $\begin{array}{c}\text { Activation } \\
\text { of hidden } \\
\text { layer }\end{array}$ & $\begin{array}{c}\text { Output } \\
\text { activation } \\
\text { function }\end{array}$ \\
\hline 1 & $\begin{array}{c}\text { MLP } \\
3-8-1\end{array}$ & 0.978219 & 0.977584 & 0.972223 & 240497.8 & 265214.2 & 361000.2 & $\begin{array}{c}\text { BFGS (Quasi- } \\
\text { Newton) 206 }\end{array}$ & $\begin{array}{c}\text { Sum of } \\
\text { squares }\end{array}$ & Exponent. & Exponent. \\
\hline 2 & $\begin{array}{c}\text { MLP } \\
3-7-1\end{array}$ & 0.980139 & 0.978288 & 0.974421 & 219420.0 & 256942.3 & 319577.7 & $\begin{array}{c}\text { BFGS (Quasi- } \\
\text { Newton) 9999 }\end{array}$ & $\begin{array}{c}\text { Sum of } \\
\text { squares }\end{array}$ & Exponent. & Logistic \\
\hline 3 & $\begin{array}{c}\text { MLP } \\
3-8-1\end{array}$ & 0.982555 & 0.976820 & 0.976856 & 192860.0 & 272205.3 & 289849.3 & $\begin{array}{c}\text { BFGS (Quasi- } \\
\text { Newton) 318 }\end{array}$ & $\begin{array}{c}\text { Sum of } \\
\text { squares }\end{array}$ & Tanh & Identity \\
\hline 4 & $\begin{array}{c}\text { MLP } \\
3-10-1\end{array}$ & 0.978333 & 0.975024 & 0.972400 & 239137.9 & 293338.6 & 361366.5 & $\begin{array}{c}\text { BFGS (Quasi- } \\
\text { Newton) 154 }\end{array}$ & $\begin{array}{c}\text { Sum of } \\
\text { squares }\end{array}$ & Exponent. & Exponent. \\
\hline 5 & $\begin{array}{c}\text { MLP } \\
3-8-1\end{array}$ & 0.977693 & 0.973863 & 0.973028 & 246149.5 & 307303.0 & 349478.2 & $\begin{array}{c}\text { BFGS (Quasi- } \\
\text { Newton) 168 }\end{array}$ & $\begin{array}{c}\text { Sum of } \\
\text { squares }\end{array}$ & Exponent. & Exponent. \\
\hline
\end{tabular}

Source: Authors.

It results from the table that the neural networks with 7-10 neurons in the hidden layer were retained. The input layer of the neural networks contains always three neurons (date, month, and a year in which the values were measured). For the activation of the hidden layer, the exponential function and hyperbolic tangent are used. The output layer of neurons is activated using the exponential, identity and logistic functions. The neural networks performance is also important. It is expressed by a correlation coefficient, which achieves very high values in all datasets of all neural networks. In the case of Training dataset, the correlation coefficient achieves the values of more than 0.97 to more than 0.98. The correlation coefficient is high also in the case of the testing dataset (always nearly 0.98). Optically weakest performance is shown by the Testing dataset, although achieving always more than 0.97 . This indicates a high level of direct dependence. This parameter shows that the retained neural structures are a reliable model of an actual time series and should have the ability to forecast the future development of the time series very accurately (if it does not suffer from overfitting ${ }^{2}$ ). It shall also be noted that the errors calculated using the method of least squares are acceptable.

Graph 2 shows the comparison of the actual course of time series and smoothed time series.

\footnotetext{
${ }^{2}$ Overfitting is characterized by the fact that neural networks smooth the time series relatively well, show perfect performance, minimum error, but the prediction of the time series future development is factually nonsensical.
} 
Graph 2: Smoothed time series of retained networks in Experiment 1

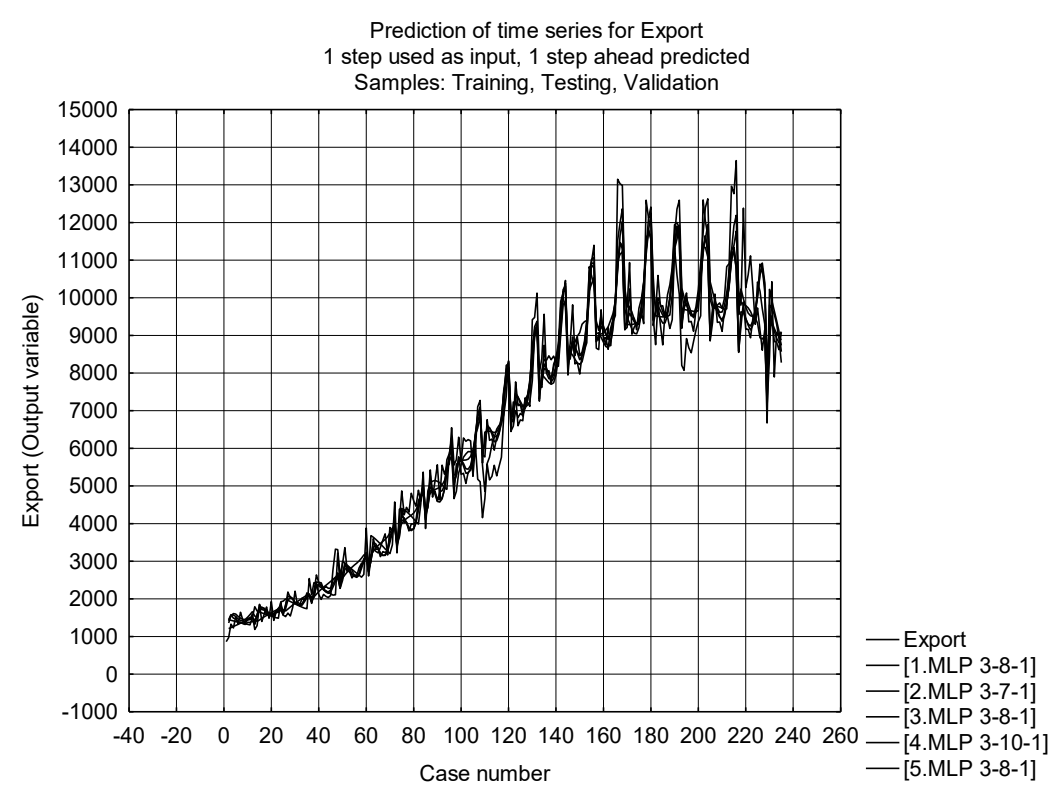

Source: Authors.

Graph 2 clearly shows that all smoothed time series are able to follow the actual development of the USA export to the PRC quite well. With some small exceptions (or relatively small deviations), all are able to capture the development trend as well as time series fluctuations.

In order to be able to determine whether the networks are applicable or not, we will focus on their application in forecasting. We will forecast the development of the USA export to the PRC for the period between August 2019 and December 2020. The specific data can be seen in Table 3. 
Tab. 3: Development of predictions for August 2019-December 2020 by networks retained in Experiment 1

\begin{tabular}{|r|r|r|r|r|r|}
\hline \multicolumn{1}{|c|}{ Date } & MLP 3-8-1 & MLP 3-7-1 & MLP 3-8-1 & \multicolumn{1}{c|}{ MLP 3-10-1 } & \multicolumn{1}{c|}{ MLP 3-8-1 } \\
\hline 31 August 2019 & $9,311.689$ & $7,453.37$ & 7,554 & $9,170.906$ & $9,347.852$ \\
\hline 30 September 2019 & 863.100 & $13,147.80$ & 2,081 & $1,755.334$ & $4,243.840$ \\
\hline 31 October 2019 & 863.100 & $13,147.80$ & $-18,531$ & 939.437 & $2,127.092$ \\
\hline 30 November 2019 & 863.100 & $13,147.80$ & $-70,749$ & 866.953 & $1,260.583$ \\
\hline 31 December 2019 & 863.100 & $13,147.80$ & $-147,143$ & 863.217 & 967.389 \\
\hline 31 January 2020 & 863.100 & $13,147.80$ & $-211,085$ & 863.101 & 881.727 \\
\hline 29 February 2020 & 863.100 & $12,684.06$ & $-36,108$ & 863.273 & $1,574.304$ \\
\hline 31 March 2020 & 863.100 & $13,143.35$ & $-99,156$ & 863.115 & $1,283.547$ \\
\hline 30 April 2020 & 863.100 & $13,147.80$ & $-177,556$ & 863.101 & $1,092.410$ \\
\hline 31 May 2020 & 863.100 & $13,147.80$ & $-224,838$ & 863.100 & 982.952 \\
\hline 30 June 2020 & 863.100 & $13,147.80$ & $-243,667$ & 863.100 & 921.501 \\
\hline 31 July 2020 & 863.100 & $13,147.80$ & $-249,076$ & 863.100 & 890.145 \\
\hline 31 August 2020 & 863.100 & $13,147.80$ & $-249,795$ & 863.100 & 874.573 \\
\hline 30 September 2020 & 863.100 & $13,147.80$ & $-250,490$ & 863.100 & 867.543 \\
\hline 31 October 2020 & 863.100 & $13,147.80$ & $-251,150$ & 863.100 & 864.654 \\
\hline 30 November 2020 & 863.100 & $13,147.80$ & $-252,516$ & 863.100 & 863.557 \\
\hline 31 December 2020 & 863.100 & $13,147.80$ & $-256,609$ & 863.100 & 863.209 \\
\hline
\end{tabular}

Source: Authors.

Obviously, the network 3. MLP 3-8-1 predicts further development of the monitored variable nonsensically. It even shows negative values of import, which is not actually possible. The network obviously suffers from overfitting. There are also significant differences between other neural networks (or between 2. MLP 3-7-1 and other retained networks). For choosing the most successful neural network, Graph 3 (development of time series and predictions) will be used. 
Graph 3: Development of time series and predictions by networks retained in Experiment 1

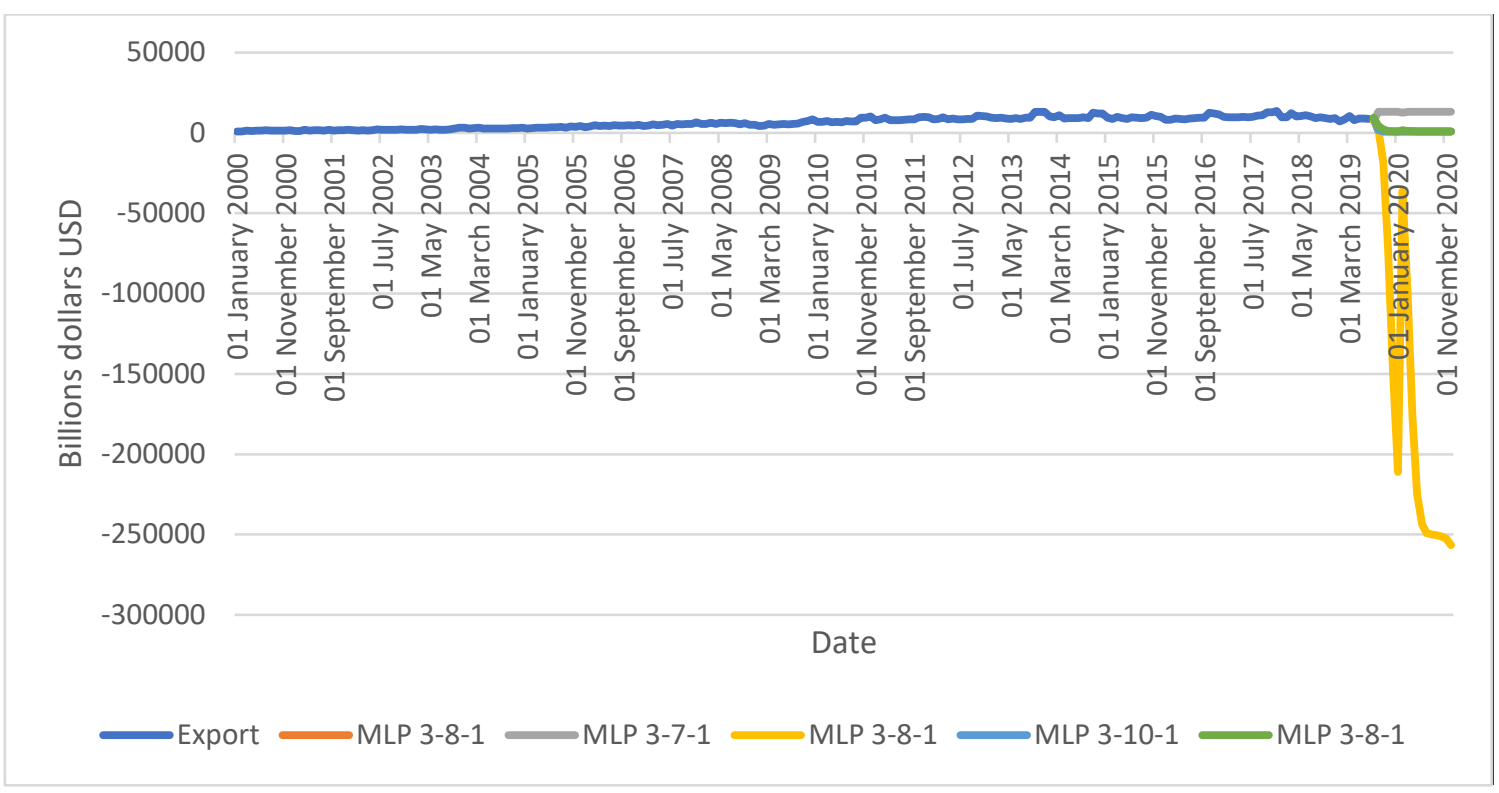

Source: Authors.

Now it is time for expert estimate. Other networks might evidently also suffer from overfitting, and a significant one. In spite of this, one network will be selected for the final comparison of the individual experiments results. 1. MLP 3-8-1, 4. MLP 3-10-1, and 5. MLP 3-8-1 show almost the same results. We will thus choose one of them. Taking into account the statistics of the smoothed time series, it can be concluded that the most successful and most accurate artificial neural network is 5. MLP 3-8-1.

\section{Experiment 2 (5-month lag in time series)}

Table 4 shows the overview of neural networks retained from Experiment 2, where the assumed time series lag is 5 months.

Tab. 4: Retained neural networks from Experiment 2

\begin{tabular}{|c|c|c|c|c|c|c|c|c|c|c|c|}
\hline Index & Network & $\begin{array}{c}\text { Training } \\
\text { perform. }\end{array}$ & $\begin{array}{c}\text { Test. } \\
\text { perform. }\end{array}$ & $\begin{array}{c}\text { Valid. } \\
\text { perform. }\end{array}$ & $\begin{array}{c}\text { Training } \\
\text { error }\end{array}$ & $\begin{array}{c}\text { Testing } \\
\text { error }\end{array}$ & $\begin{array}{c}\text { Valid. } \\
\text { error }\end{array}$ & $\begin{array}{c}\text { Training } \\
\text { algorithm }\end{array}$ & $\begin{array}{c}\text { Error } \\
\text { function }\end{array}$ & $\begin{array}{c}\text { Activation of } \\
\text { hidden layer }\end{array}$ & $\begin{array}{c}\text { Output } \\
\text { activation } \\
\text { function }\end{array}$ \\
\hline 1 & $\begin{array}{c}\text { MLP } \\
15-7-1\end{array}$ & 0.973572 & 0.966155 & 0.972225 & 286349.4 & 338708.9 & 333663.0 & $\begin{array}{c}\text { BFGS (Quasi- } \\
\text { Newton) 67 }\end{array}$ & $\begin{array}{c}\text { Sum of } \\
\text { squares }\end{array}$ & Exponential & Logistic \\
\hline 2 & $\begin{array}{c}\text { MLP } \\
15-10-1\end{array}$ & 0.973730 & 0.963486 & 0.972162 & 284104.3 & 360204.8 & 317915.7 & $\begin{array}{c}\text { BFGS (Quasi- } \\
\text { Newton) 77 }\end{array}$ & $\begin{array}{c}\text { Sum of } \\
\text { squares }\end{array}$ & Exponential & Logistic \\
\hline 3 & $\begin{array}{c}\text { MLP } \\
\text { N-8-1 }\end{array}$ & 0.974078 & 0.962645 & 0.973662 & 280208.0 & 366654.9 & 303239.0 & $\begin{array}{c}\text { BFGS (Quasi- } \\
\text { Newton) 93 }\end{array}$ & $\begin{array}{c}\text { Sum of } \\
\text { squares }\end{array}$ & Exponential & Logistic \\
\hline 4 & $\begin{array}{c}\text { MLP } \\
\text { N-7-1 }\end{array}$ & 0.973724 & 0.963440 & 0.973038 & 283899.5 & 362903.6 & 308651.9 & $\begin{array}{c}\text { BFGS (Quasi- } \\
\text { Newton) 80 }\end{array}$ & $\begin{array}{c}\text { Sum of } \\
\text { squares }\end{array}$ & Exponential & Logistic \\
\hline 5 & $\begin{array}{c}\text { MLP } \\
\text { N-7-1 }\end{array}$ & 0.973842 & 0.961769 & 0.972307 & 282599.9 & 371616.4 & 323001.7 & $\begin{array}{c}\text { BFGS (Quasi- } \\
\text { Newton) 74 }\end{array}$ & $\begin{array}{c}\text { Sum of } \\
\text { squares }\end{array}$ & Exponential & Logistic \\
\hline
\end{tabular}

Source: Authors.

In Experiment 2, the input layer contains 15 neurons. The table shows that the neural networks with 7-10 neurons in the hidden layer of the neural network were retained. For the activation of the hidden layer, exponential function is used. The output layer is always 
activated by means of the logistic function. The performance of artificial neural networks measured by means of the correlation coefficient is above 0.97 in the training dataset, above 0.96 in the testing dataset, and above 0.97 in the validation dataset. This indicates a high level of direct dependence in all cases. Based on this parameter, it could be said that the networks (if not suffering from overfitting) will be able to forecast further development of the USA export to the PRC very accurately (since they smoothed the time series in the past very well). For the calculation of the error, method of least squares was used. In the case of export, the error is not big, and it also gives a quality prediction of the time series. Graph 4 shows the comparison of the actual course of the time series and smoothed time series.

Graph 4: Smoothed time series of networks retained in Experiment 2

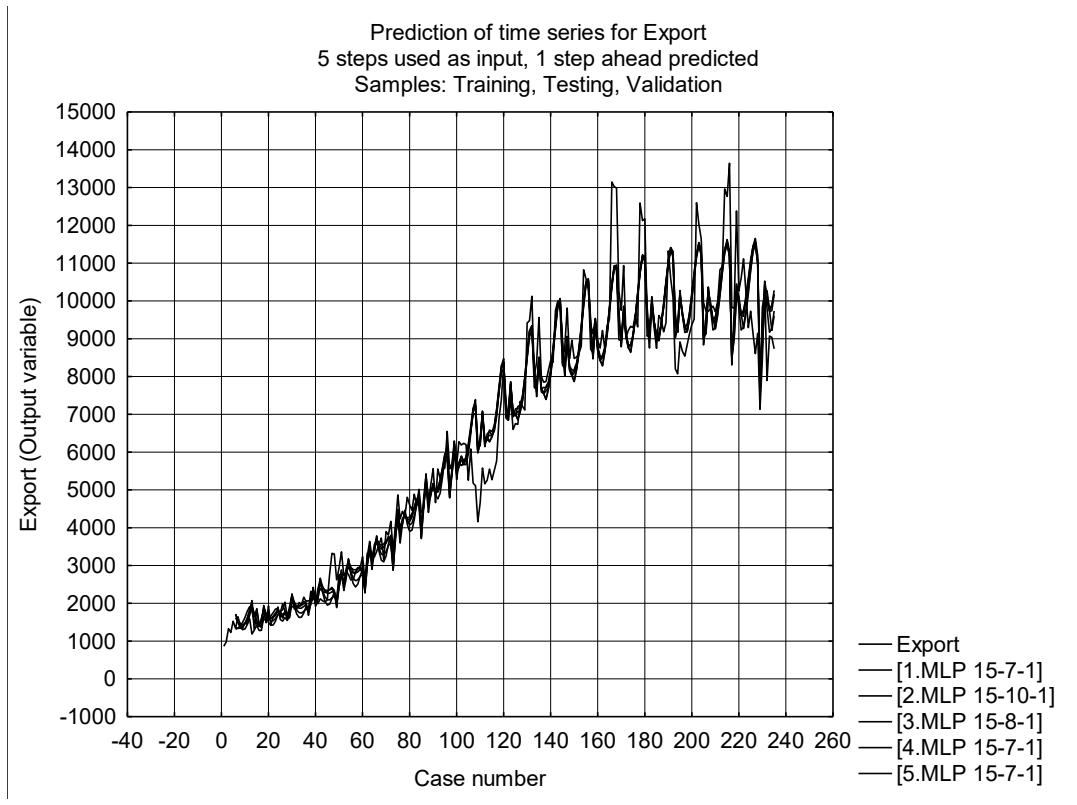

Source: Authors.

It is evident from Graph 4 that all smoothed time series are able to capture the development of the actual development of the USA export to the PRC. The course of all smoothed time series is very similar to each other. The neural networks were able to capture the development trend as well as the seasonal fluctuations. However, they do not follow some extreme fluctuations completely. This refers mainly to the cases around the case No. 115, specifically from November 2008 to August 2009.

Also, in the case of export we will deal with the forecast of the future development of the monitored variable. We will forecast the development of the USA export to the PRC for the period between August 2019 and December 2020. Concrete data are shown in Table 5. 
Tab. 5: Forecasts development between August 2019 and January 2020 by networks retained in Experiment 2

\begin{tabular}{|l|r|r|r|r|r|}
\hline \multicolumn{1}{|c|}{ Date } & MLP 15-7-1 & MLP 15-10-1 & MLP 15-8-1 & MLP 15-7-1 & \multicolumn{1}{c|}{ MLP 15-7-1 } \\
\hline 31 August 2019 & $10,279.81$ & $10,739.16$ & $10,617.62$ & $10,166.11$ & $10,654.85$ \\
\hline 30 September 2019 & $10,814.64$ & $11,132.83$ & $11,098.27$ & $10,731.32$ & $11,111.66$ \\
\hline 31 October 2019 & $11,242.17$ & $11,337.84$ & $11,492.52$ & $11,230.89$ & $11,446.66$ \\
\hline 30 November 2019 & $11,295.93$ & $11,009.44$ & $11,566.69$ & $11,264.85$ & $11,425.88$ \\
\hline 31 December 2019 & $10,259.31$ & $8,417.86$ & $10,360.17$ & $9,751.11$ & $10,235.95$ \\
\hline 31 January 2020 & $5,031.43$ & $1,788.88$ & $3,628.02$ & $3,083.52$ & $4,019.12$ \\
\hline 29 February 2020 & $7,959.24$ & $8,028.68$ & $6,683.97$ & $9,776.34$ & $6,899.30$ \\
\hline 31 March 2020 & $9,160.78$ & $9,694.63$ & $9,285.55$ & $8,493.03$ & $8,691.60$ \\
\hline 30 April 2020 & $8,703.29$ & $9,826.61$ & $10,223.28$ & $9,339.56$ & $9,543.56$ \\
\hline 31 May 2020 & $7,939.71$ & $9,665.11$ & $9,824.08$ & $9,601.72$ & $9,605.19$ \\
\hline 30 June 2020 & $8,155.12$ & $9,539.10$ & $9,897.51$ & $7,796.75$ & $9,894.66$ \\
\hline 31 July 2020 & $8,455.32$ & $9,508.48$ & $10,030.46$ & $7,752.58$ & $10,175.60$ \\
\hline 31 August 2020 & $8,756.21$ & $9,206.95$ & $10,148.73$ & $7,700.18$ & $10,365.98$ \\
\hline 30 September 2020 & $8,906.66$ & $8,228.94$ & $10,044.15$ & $7,316.84$ & $10,290.13$ \\
\hline 31 October 2020 & $8,566.82$ & $5,725.59$ & $9,195.68$ & $5,868.67$ & $9,469.96$ \\
\hline 30 November 2020 & $6,921.72$ & $2,075.81$ & $6,110.72$ & $2,740.77$ & $6,474.23$ \\
\hline 31 December 2020 & $3,128.68$ & 897.84 & $1,536.10$ & 956.15 & $1,707.44$ \\
\hline
\end{tabular}

Source: Authors.

The results in the table represent a possible development of the time series. This is partly confirmed by the graph in Graph 5.

Graph 5: Development of time series and predictions by networks retained in Experiment 2



$\longrightarrow$ Export $\longrightarrow$ MLP 15-7-1 MLP 15-10-1 2 MLP 15-8-1 $\longrightarrow$ MLP 15-7-1 $\longrightarrow$ MLP 15-7-1

Source: Authors.

If we compare the actual development of the USA export to the PRC and the assumed development of the variable over time forecast by artificial neural networks retained in 
smoothing the export time series, it could be concluded, that the best predictions of the networks future development are provided by 1. MLP 15-7-1.

\section{Experiment 3 (10-month lag in time series)}

Within Experiment 3, 10,000 artificial neural networks were generated as well, and out of them 5 with the best characteristics were retained (for more detail, see Table 6).

Tab. 6: Retained neural networks from Experiment 3

\begin{tabular}{|c|c|c|c|c|c|c|c|c|c|c|c|}
\hline Index & Network & $\begin{array}{c}\text { Training } \\
\text { perform. }\end{array}$ & $\begin{array}{c}\text { Test. } \\
\text { perform. }\end{array}$ & $\begin{array}{c}\text { Valid. } \\
\text { perform. }\end{array}$ & Training & Testing & Valid. & Training & Error \\
error & error & $\begin{array}{c}\text { Activation } \\
\text { algorithm } \\
\text { of hidden } \\
\text { function }\end{array}$ & $\begin{array}{c}\text { Output } \\
\text { activation } \\
\text { function }\end{array}$ \\
\hline 1 & MLP & 0.985091 & 0.971938 & 0.973574 & 127979.9 & 256473.4 & 295789.7 & $\begin{array}{c}\text { BFGS (Quasi- } \\
\text { Newton) 115 }\end{array}$ & $\begin{array}{c}\text { Sum of } \\
\text { squares }\end{array}$ & Tanh & Exponential \\
\hline 2 & $\begin{array}{c}\text { MLP } \\
\text { No-7-1 }\end{array}$ & 0.973185 & 0.963315 & 0.974023 & 249204.1 & 375681.7 & 307967.3 & $\begin{array}{c}\text { BFGS (Quasi- } \\
\text { Newton) 56 }\end{array}$ & $\begin{array}{c}\text { Sum of } \\
\text { squares }\end{array}$ & Exponential & Logistic \\
\hline 3 & $\begin{array}{c}\text { MLP } \\
30-9-1\end{array}$ & 0.971367 & 0.958293 & 0.971346 & 266211.7 & 427132.6 & 354171.7 & $\begin{array}{c}\text { BFGS (Quasi- } \\
\text { Newton) 54 }\end{array}$ & $\begin{array}{c}\text { Sum of } \\
\text { squares }\end{array}$ & Tanh & Tanh \\
\hline 4 & $\begin{array}{c}\text { MLP } \\
\text { Sq-4-1 }\end{array}$ & 0.974992 & 0.961217 & 0.971614 & 230192.7 & 382435.6 & 348428.8 & $\begin{array}{c}\text { BFGS (Quasi- } \\
\text { Newton) 78 }\end{array}$ & $\begin{array}{c}\text { Sum of } \\
\text { squares }\end{array}$ & Exponential & Exponential \\
\hline 5 & MLP & 0.977887 & 0.971500 & 0.972325 & 200683.0 & 262408.4 & 349029.4 & $\begin{array}{c}\text { BFGS (Quasi- } \\
\text { Newton) 57 }\end{array}$ & $\begin{array}{c}\text { Sum of } \\
\text { squares }\end{array}$ & Tanh & Exponential \\
\hline
\end{tabular}

Source: Authors.

The results of this experiment show that the input layer contains 30 neurons (date, month, year with 10-month lag). It results from the table that the neural networks with 4-9 neurons in the hidden layer were retained. For the activation of the hidden layer, neural networks use the function of hyperbolic tangent, logistic function, and exponential function. The output layer of neurons is activated by means of the exponential function, logistic function, and the function of hyperbolic tangent. The performance of the neural networks is also important. The correlation coefficient achieves very high values in all datasets: always nearly 0.98 or even 0.99 in the training dataset, above 0.97 in the testing dataset, as well as in the case of the validation dataset. Here we can also state a high degree of direct dependence. On the basis of this parameter, it is evident that the retained neural structures are a reliable model of the actual time series, and are thus able to predict the future development of the time series. For the calculation of the error, the method of least squares was used. But even here, the error is not big, and gives assumption of quality prediction of the time series. Graph 6 shows the comparison of the actual course of time series and smoothed time series. 
Graph 6: Smoothed time series retained in Experiment 3

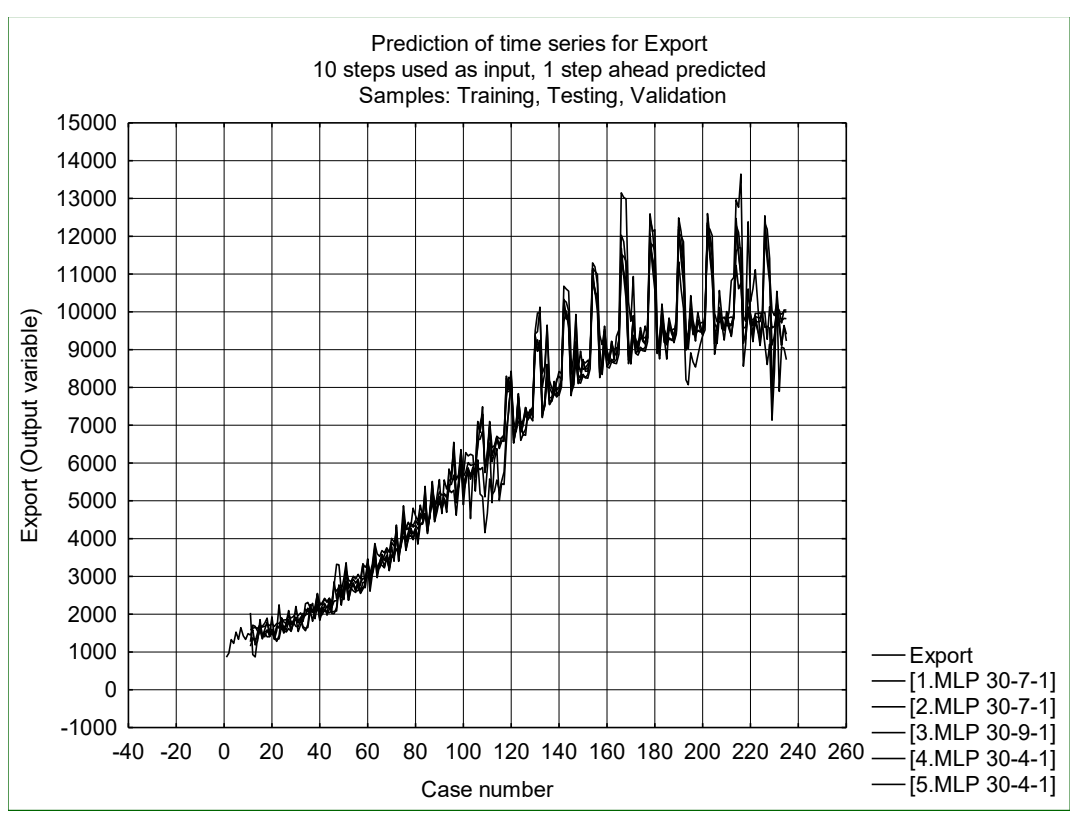

Source: Authors.

Graph 6 shows that all retained neural networks are able to follow the course of the actual development of the USA export to the PRC; moreover, the course of all smoothed time series is very similar to each other. The neural networks are able to capture the development trend as well as the local extremes (in very reliable way!).

In the case of 10-month lag, we will also deal with the prediction of the future development of the monitored variable. We will forecast the development of the USA export to the PRC for the period between August 2019 and December 2020. Concrete data are shown in Table 7. 
Tab. 7: Development of predictions for August 2019-December2020 by networks retained in Experiment 3

\begin{tabular}{|l|r|r|r|r|r|}
\hline \multicolumn{1}{|c|}{ Date } & MLP 30-7-1 & \multicolumn{1}{c|}{ MLP 30-7-1 } & MLP 30-9-1 & MLP 30-4-1 & \multicolumn{1}{c|}{ MLP 30-4-1 } \\
\hline 31 August 2019 & $10,058.88$ & $8,663.91$ & $9,980.19$ & $9,199.18$ & $9,814.631$ \\
\hline 30 September 2019 & $9,980.44$ & $9,025.32$ & $10,146.20$ & $9,639.07$ & $9,991.784$ \\
\hline 31 October 2019 & $9,449.71$ & $12,209.91$ & $12,589.54$ & $11,649.85$ & $8,427.897$ \\
\hline 30 November 2019 & $9,432.04$ & $12,071.29$ & $11,615.31$ & $10,929.22$ & $7,552.713$ \\
\hline 31 December 2019 & $9,287.95$ & $10,904.09$ & $11,063.09$ & $10,254.92$ & $9,024.839$ \\
\hline 31 January 2020 & $7,522.85$ & $6,174.31$ & $10,241.32$ & $8,714.76$ & $9,430.280$ \\
\hline 29 February 2020 & $9,462.77$ & $7,310.10$ & $10,139.62$ & $8,833.07$ & $9,474.664$ \\
\hline 31 March 2020 & $10,144.73$ & $9,422.99$ & $10,428.04$ & $9,087.77$ & $9,771.404$ \\
\hline 30 April 2020 & $10,161.47$ & $7,722.10$ & $10,247.71$ & $8,683.64$ & $9,722.581$ \\
\hline 31 May 2020 & $9,873.73$ & $6,063.00$ & $10,243.50$ & $8,166.54$ & $9,716.360$ \\
\hline 30 June 2020 & $10,184.83$ & $5,626.68$ & $10,325.84$ & $8,414.12$ & $9,905.207$ \\
\hline 31 July 2020 & $10,191.02$ & $4,356.64$ & $10,334.27$ & $8,144.17$ & $9,926.569$ \\
\hline 31 August 2020 & $10,204.51$ & $2,889.16$ & $10,343.70$ & $7,896.86$ & $9,806.443$ \\
\hline 30 September 2020 & $9,890.54$ & $1,752.53$ & $10,431.99$ & $8,132.15$ & $9,655.198$ \\
\hline 31 October 2020 & $9,566.93$ & $4,331.46$ & $12,533.29$ & $9,365.36$ & $4,656.181$ \\
\hline 30 November 2020 & $9,549.53$ & $6,182.45$ & $11,398.10$ & $8,760.23$ & $3,673.030$ \\
\hline 31 December 2020 & $9,313.62$ & $1,809.09$ & $10,965.42$ & $8,119.01$ & $4,125.885$ \\
\hline
\end{tabular}

Source: Authors.

As already stated above, smoothed time series are very similar to each other. The table, however, shows that some of the neural networks suffer from overfitting, which is partly confirmed by the graph in Graph 7.

Graph 7: Development of time series and predictions by networks retained in Experiment 3



Source: Authors. 
The graph shows that 2. MLP 30-7-1 and 5. MLP 30-4-1 suffer from overfitting. They can thus be excluded from the further consideration. When comparing the remaining three neural networks (based both on their graphical course and the characteristics of all networks), it can be concluded that the network 4. MLP 30-4-1 shows the best predictions.

\section{Discussion}

Within this research, three experiments were carried out, where the development of the time series represented by the USA export to the PRC were investigated. It was primarily observed how multilayer perceptron networks are able to smooth time series, mainly with regard to the development from 2018 (when the trade war of the two countries was launched). In each experiment, 10,000 artificial neural networks were generated, out of which five best structures were retained. Some of them evidently suffered from overfitting. This refers to the neural networks from the Experiments one and three. Others are applicable for forecasting the future development of the USA export to the PRC. In all cases, the performance of the networks was high, while the error was small. In each experiment, the best network was identified and it was subject to further comparison (for more details, see Table 8).

Tab. 8: Comparison of most successful neural networks from all three experiments

\begin{tabular}{|l|r|r|r|}
\hline \multirow{2}{*}{ Date } & Experiment 1 & Experiment 2 & Experiment 3 \\
\cline { 2 - 4 } & 5. MLP 3-8-1 & 1. MLP 15-7-1 & 4. MLP 30-4-1 \\
\hline 31 August 2019 & $9,347.852$ & $10,279.81$ & $9,199.18$ \\
\hline 30 September 2019 & $4,243.840$ & $10,814.64$ & $9,639.07$ \\
\hline 31 October 2019 & $2,127.092$ & $11,242.17$ & $11,649.85$ \\
\hline 30 November 2019 & $1,260.583$ & $11,295.93$ & $10,929.22$ \\
\hline 31 December 2019 & 967.389 & $10,259.31$ & $10,254.92$ \\
\hline 31 January 2020 & 881.727 & $5,031.43$ & $8,714.76$ \\
\hline 29 February 2020 & $1,574.304$ & $7,959.24$ & $8,833.07$ \\
\hline 31 March 2020 & $1,283.547$ & $9,160.78$ & $9,087.77$ \\
\hline 30 April 2020 & $1,092.410$ & $8,703.29$ & $8,683.64$ \\
\hline 31 May 2020 & 982.952 & $7,939.71$ & $8,166.54$ \\
\hline 30 June 2020 & 921.501 & $8,155.12$ & $8,414.12$ \\
\hline 31 July 2020 & 890.145 & $8,455.32$ & $8,144.17$ \\
\hline 31 August 2020 & 874.573 & $8,756.21$ & $7,896.86$ \\
\hline 30 September 2020 & 867.543 & $8,906.66$ & $8,132.15$ \\
\hline 31 October 2020 & 864.654 & $8,566.82$ & $9,365.36$ \\
\hline 30 November 2020 & 863.557 & $6,921.72$ & $8,760.23$ \\
\hline 31 December 2020 & 863.209 & $3,128.68$ & $8,119.01$ \\
\hline
\end{tabular}

Source: Authors. 
Table 8 indicates the differences between the neural networks, and indicates that the differences are significant. This is even better shown by Graph 8.

Graph 8: Comparison of most successful neural structures from all three experiments

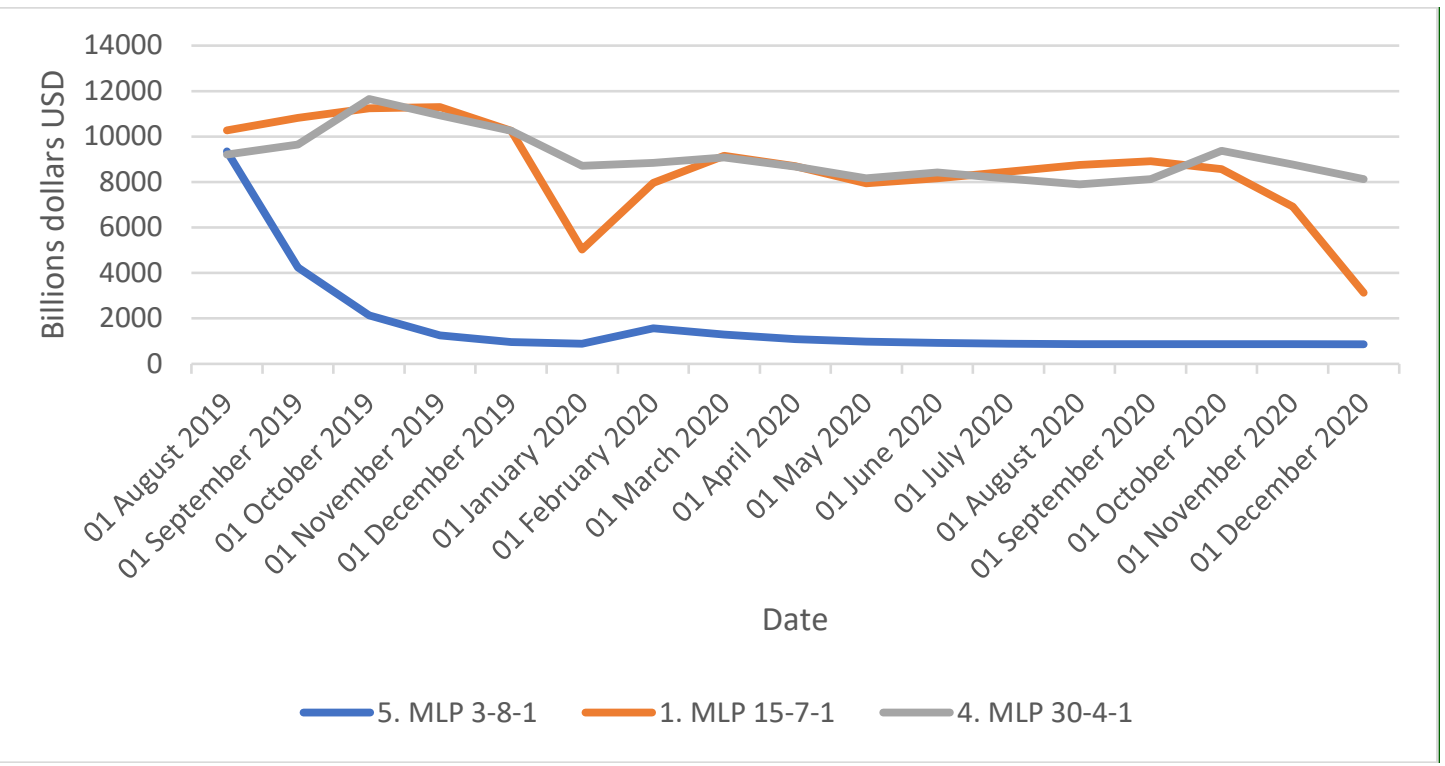

Source: Authors.

The figure shows a very different course of the neural network from the first experiment and other neural networks. However, the neural network from the first experiment was included only formally, as it was clear at the beginning that the network suffers from overfitting. As for the neural networks from the other two experiments, their course is less different from each other. However, it is evident that the neural network retained in the second experiment assumes a very extreme development - a fall in the USA export to the PRC. If we considered the unbalanced development of this time series, we would probably choose the network from the second experiment as the most successful one. However, due to the law of large numbers, it is not likely that the development of the network at the end of the monitored period would by as extreme as the prediction of the network retained from the second experiment indicates. We thus choose the network retained from Experiment 3 - 4. MLP 30-4-1. It is thus evident that 10-month lag was positive for the structure of the network and its predictions.

\section{Conclusion}

The objective of the article was to forecast the export of the United States of America to the People's Republic of China.

It can be stated that the objective of the contribution was achieved:

1. Multilayer perceptron networks appear to be an excellent tool for forecasting the USA export to the PRC.

2. MLP networks are able to capture both the trend of the whole time series and its fluctuations. Despite of this, it must be stated that in the area of the USA export to 
the PRC, there are no long-term mutually beneficial and stable relationships. The time series thus show unexplainable fluctuations.

3. Time series lag has to be applied. Acceptable results have been shown in the case of a 10-month lag.

4. The reciprocal sanctions of both countries significantly affected the USA export to the PRC but they did not affect significantly the result of machine learning forecasting. This is mainly due to the fact, that only some artificial neural networks are subjected to analyses and subsequently tested. This eliminates the probability that the suitable neural network will not suffer from overfitting. However, it can be assumed that in the case of the research of time series, overfitting was caused by the gradation of the trade war between the USA and the PRC.

Further research shall be focused on the elimination of overfitting in time series forecasting.

\section{References}

1. AUER, R., A. M. FISCHER, 2010. The effect of low-wage import competition on US inflationary pressure. Journal of Monetary Economics, 57(4), 491-503.

2. BERNHOFEN, D., R. UPWARD, Z. WANG, 2018. Quantity restrictions and price adjustment of Chinese Textile Exports to the US. The World Economy, 41(11), 2983-3000.

3. DOAN, H. T. T., T. Q. LONG, 2019. Technical Change, Exports, and Employment Growth in China: A Structural Decomposition Analysis. Asian Economic Papers, 18(2), 28-46.

4. DAVID, H., D. DORN, G. H. HANSON, 2013. The China syndrome: Local labor market effects of import competition in the United States. American Economic Review, 103(6), 2121-68.

5. FEENSTRA, R. C., A. SASAHARA, 2018. The 'China shock,' exports and US employment: A global input-output analysis. Review of International Economics, 26(5), 1053-1083.

6. HALLAK, J. C., 2006. Product quality and the direction of trade. Journal of international Economics, 68(1), 238-265.

7. HANDLEY, K., N. LIMÃO, 2017. Policy uncertainty, trade, and welfare: Theory and evidence for china and the United States. American Economic Review, 107(9), 2731-83.

8. HUMMELS, D., P. J. KLENOW, 2005. The variety and quality of a nation's exports. American Economic Review, 95(3), 704-723.

9. LI, S. et al., 2019. China's export evolution in the dynamic global product space from 2000 to 2011. Current Science (00113891), 117(3).

10. LIN, G., F. WANG, J. PEI, 2018. Global value chain perspective of US-China trade and employment. The World Economy, 41(8), 1941-1964.

11. RODRIGUE, J., Y. TAN, 2019. Price, product quality, and exporter dynamics: Evidence from China. International Economic Review. 
12. SCHOTT, P. K., 2008. The relative sophistication of Chinese exports. Economic policy, 23(53), 6-49.

13. SOKOLOV-MLADENOVIĆ, S. et al., 2016. Economic growth forecasting by artificial neural network with extreme learning machine based on trade, import and export parameters. Computers in Human Behavior, 65, 43-45.

14. ÜLKE, V., A. SAHIN, A. SUBASI, 2018. A comparison of time series and machine learning models for inflation forecasting: empirical evidence from the USA. Neural Computing and Applications, 30(5), 1519-1527.

15. WANG, Z., Z. YU, 2012. Trading partners, traded products and firm performances of China's exporter-importers: does processing trade make a difference? The World Economy, 35(12), 1795-1824.

\section{Contact address of the authors:}

Ing. Tomáš Krulický, BBA, School of Valuation and Expertness, Institute of Technology and Business in České Budějovice, Okružní 517/10, České Budějovice 37001, Czech Republic, e-mail: krulicky@mail.vstecb.cz

Bc. Eva Kalinová, School of Valuation and Expertness, Institute of Technology and Business in České Budějovice, Okružní 517/10, České Budějovice 37001, Czech Republic, e-mail: jessica@mail.vstecb.cz

Ing. Jiřri Kučera, School of Valuation and Expertness, Institute of Technology and Business in České Budějovice, Okružní 517/10, České Budějovice 37001, Czech Republic, e-mail: kuceraj@mail.vstecb.cz 